Glasgow Caledonian

University

University for the Common Good

\title{
Restrictions for reimbursement of interferon-free direct-acting antiviral drugs for HCV infection in Europe
}

Marshall, Alison D.; Cunningham, Evan B.; Nielsen, Stine; Aghemo, Alessio; Alho, Hannu; Backmund, Markus; Bruggmann, Philip; Dalgard, Olav; Seguin-Devaux, Carole; Flisiak, Robert; Foster, Graham R.; Gheorghe, Liana; Goldberg, David; Goulis, Ioannis; Hickman, Matthew; Hoffmann, Patrick; Jancoriene, Ligita; Jarcuska, Peter; Kåberg, Martin; Kostrikis, Leondios G.; Makara, Mihály; Maimets, Matti; Marinho, Rui Tato; Maticic, Mojca; Norris, Suzanne; Ólafsson, Sigurður; Øvrehus, Anne; Pawlotsky, Jean-Michel; Pocock, James; Robaeys, Geert; Roncero, Carlos; Simonova, Marieta; Sperl, Jan; Tait, Michele; Tolmane, leva; Tomaselli, Stefan; van der Valk, Marc; Vince, Adriana; Dore, Gregory J.; Lazarus, Jeffrey V.; Grebely, Jason

Published in:

The Lancet Gastroenterology \& Hepatology

DOI:

$10.1016 / \mathrm{S} 2468-1253(17) 30284-4$

Publication date:

2018

Document Version

Author accepted manuscript

Link to publication in ResearchOnline

Citation for published version (Harvard):

Marshall, AD, Cunningham, EB, Nielsen, S, Aghemo, A, Alho, H, Backmund, M, Bruggmann, P, Dalgard, O, Seguin-Devaux, C, Flisiak, R, Foster, GR, Gheorghe, L, Goldberg, D, Goulis, I, Hickman, M, Hoffmann, P, Jancoriene, L, Jarcuska, P, Kåberg, M, Kostrikis, LG, Makara, M, Maimets, M, Marinho, RT, Maticic, M, Norris, S, Ólafsson, S, Øvrehus, A, Pawlotsky, J-M, Pocock, J, Robaeys, G, Roncero, C, Simonova, M, Sperl, J, Tait, M, Tolmane, I, Tomaselli, S, van der Valk, M, Vince, A, Dore, GJ, Lazarus, JV \& Grebely, J 2018, 'Restrictions for reimbursement of interferon-free direct-acting antiviral drugs for HCV infection in Europe', The Lancet

Gastroenterology \& Hepatology, vol. 3, no. 2, pp. 125-133. https://doi.org/10.1016/S2468-1253(17)30284-4

Copyright and moral rights for the publications made accessible in the public portal are retained by the authors and/or other copyright owners and it is a condition of accessing publications that users recognise and abide by the legal requirements associated with these rights. 


\title{
Restrictions for reimbursement of interferon-free direct-acting antiviral drugs for HCV infection in Europe
}

\begin{abstract}
Alison D Marshall, Evan B Cunningham, Stine Nielsen, Alessio Aghemo, Hannu Alho, Markus Backmund, Philip Bruggmann, Olav Dalgard, Carole Seguin-Devaux, Robert Flisiak, Graham R Foster, Liana Gheorghe, David Goldberg, loannis Goulis, Matthew Hickman, Patrick Hoffmann, Ligita Jancorienè, Peter Jarcuska, Martin Kaberg, Leondios G Kostrikis, Mihaly Makara, Matti Maimets, Rui Tato Marinho, Mojca Matičič, Suzanne Norris, Sigurdur Olafsson, Anne Ovrehus, Jean-Michel Pawlotsky, James Pocock, Geert Robaeys, Carlos Roncero, Marieta Simonova, Jan Sperl, Michele Tait, leva Tolmane, Stefan Tomaselli, Marc van der Valk, Adriana Vince, Gregory J Dore, Jeffrey V Lazarus, Jason Grebely, on behalf of the International Network on Hepatitis in Substance Users (INHSU)
\end{abstract}

\section{Abstract}

All-oral direct-acting antiviral drugs (DAAs) for hepatitis $C$ virus, which have response rates of $95 \%$ or more, represent a major clinical advance. However, the high list price of DAAs has led many governments to restrict their reimbursement. We reviewed the availability of, and national criteria for, interferon-free DAA reimbursement among countries in the European Union and European Economic Area, and Switzerland. Reimbursement documentation was reviewed between Nov 18, 2016, and Aug 1, 2017. Primary outcomes were fibrosis stage, drug or alcohol use, prescriber type, and HIV co-infection restrictions. Among the 35 European countries and jurisdictions included, the most commonly reimbursed DAA was ombitasvir, paritaprevir, and ritonavir, with dasabuvir, and with or without ribavirin (33 [94\%] countries and jurisdictions). $16(46 \%)$ countries and jurisdictions required patients to have fibrosis at stage F2 or higher, $29(83 \%)$ had no listed restrictions based on drug or alcohol use, $33(94 \%)$ required a specialist prescriber, and $34(97 \%)$ had no additional restrictions for people co-infected with HIV and hepatitis $\mathrm{C}$ virus. These findings have implications for meeting WHO targets, with evidence of some countries not following the 2016 hepatitis C virus treatment guidelines by the European Association for the Study of Liver.

\section{Introduction}

Over 71 million people (range 63-79 million) are infected with chronic hepatitis $C$ virus (HCV) globally, with about 704000 HCV-related deaths each year (range 652 100-769 600) (1-3). Compared with pegylated interferonbased therapies, all-oral direct-acting antiviral drugs (DAAs) for HCV are more tolerable and achieve viral cure in $95 \%$ or more patients, which represents one of the best clinical advances in recent decades (4). Broad uptake of DAAs could substantially reduce the global HCV disease burden, particularly HCV-related mortality and morbidity (5-7). However, the high list price of DAA therapies in some countries has led many governments $(8,9)$ to restrict patient reimbursement based on liver fibrosis severity, drug and alcohol use, and prescriber type. A 2014 study of Medicaid reimbursement criteria for sofosbuvir in the USA showed that criteria varied by state jurisdiction (8). Most states (88\%) had restrictions based on drug and alcohol use, $74 \%$ required evidence of advanced fibrosis ( $\geq$ stage $F 3$ ), $66 \%$ had prescriber limitations, and $25 \%$ required people co-infected with HIV and HCV to have suppressed HIV RNA levels or be receiving antiretroviral therapy (8).

An updated reimbursement study by Ooka and colleagues (10) showed that, overall, restrictions had lessened over a 2-year period (2014-16). For example, 22 states required evidence of advanced fibrosis ( $\geq F 3$ ) in 2016, compared with 31 states in 2014. However, this updated study also highlighted that several of the criteria for reimbursement are inconsistent 
with clinical recommendations, which state that all people who want to be treated and have no treatment contraindications should be considered for HCV therapy (11-13). In Europe, about 3.2 million people (range 2.1 - 3.8 million) are estimated to have chronic HCV infection (14). In most European countries, injection drug use is the most common route of HCV transmission (15-17).

Although HCV incidence is decreasing overall in Europe, liver-related deaths, and the proportions of people with decompensated cirrhosis and hepatocellular carcinoma among individuals infected with HCV, are projected to increase $20-30 \%$ by 2030 if broad access to DAAs is not achieved (14). This estimation must be considered in the context of $2030 \mathrm{HCV}$ global targets set by WHO, which propose that HCV incidence is reduced by $80 \%$, that $90 \%$ of people with HCV are diagnosed, that $80 \%$ of people with HCV are treated, and that HCVrelated mortality is reduced by $65 \%$ (18). To meet WHO targets, it is crucial that countries use strategies that optimise uptake of DAAs, such as minimising restrictions for DAA reimbursement. We aimed to review the availability of interferon-free DAAs among countries in the European Union or European Economic Area, and Switzerland, and to review national criteria for reimbursement of DAA therapy among these countries.

\section{Methodology}

We reviewed the availability of reimbursed DAAs and national criteria for DAA reimbursement among countries in the European Union or European Economic Area (including England, Northern Ireland, Scotland, and Wales as separate jurisdictions) and Switzerland. Reimbursement criteria were reviewed for the following DAA regimens: sofosbuvir with ribavirin; sofosbuvir and ledipasvir with or without ribavirin; sofosbuvir and velpatasvir with or without ribavirin; ombitasvir, paritaprevir, and ritonavir, with dasabuvir, and with or without ribavirin; elbasvir and grazoprevir with or without ribavirin; and sofosbuvir and daclatasvir with or without ribavirin. Between Nov 18, 2016, and Aug 1, 2017, most data were extracted from publicly available documentation from government websites and online drug formularies (appendix $p$ 1). We also collected additional documentation (eg, national HCV guidelines) when available (appendix $\mathrm{p} 3$ ). If it was difficult to recover information, one of three study authors (ADM, EBC, or SNi) contacted the study author from the country of interest to request access.

Given that most documents were published in a language other than English, authors of this study that were from these countries were crucial to identify documents of relevance. Three authors (ADM, EBC, or SNi) did independent document searches to further support the search findings. We also contacted authors of this study from each country to provide clarification if there were inconsistencies between documents, or if additional documents were needed. If documents could not be located, this finding was categorised as not available. Information was reviewed to determine the availability of reimbursed HCV DAAs in Europe. Categories were Yes or No. If an individual was eligible to receive a specific therapy (eg, sofosbuvir and daclatasvir with or without ribavirin) but this therapy was not reimbursed, this event was categorised as No.

Based on previous HCV DAA reimbursement studies $(8,9)$ we assessed the following criteria restrictions: minimum fibrosis stage (METAVIR or equivalent), drug or alcohol use, prescriber type, and co-infection with HIV. If information for a specific criterion was not reported with the other criteria, it was categorised as none listed. Fibrosis stage was categorised as: no restriction, F2, F3, F4, other, none listed, or not available. Fibrosis stage could be assessed through liver biopsy, transient elastography, biomedical markers, or a combination of these. We anticipated that, in many countries, patients with extrahepatic manifestations (eg, cryoglobulinaemia) would be subject to different criteria than asymptomatic patients (eg, different fibrosis stage restrictions). Given that the primary 
interest of this study was to assess criteria applicable to most patients, we recorded the minimum fibrosis stage for asymptomatic patients. Drug or alcohol use was categorised as: prioritised, no restrictions, additional restrictions, none listed, or not available. Prioritised meant that people with drug or alcohol use dependencies had fewer restrictions for access to reimbursed DAAs than individuals without drug or alcohol use dependencies. No restrictions meant that people with drug or alcohol use dependencies could receive reimbursed DAAs; for example, a person who currently injected drugs (or had a history of injection use) could be offered DAAs. Additional restrictions meant that individuals with drug or alcohol use dependencies needed to fulfil further criteria before being eligible for DAA reimbursement. On the basis of previous evidence $(8,10)$ we anticipated that one example of a drug or alcohol use restriction that might be used in European countries would be a mandatory period of abstinence from substance use before therapy (eg, a 6-month period of abstinence from drug use). In addition to this restriction, we noted any other drug or alcohol use restrictions that were listed in reimbursement criteria. Prescriber type categories were: no restriction, specialist only, none listed, and not available. No restriction meant that a health-care provider other than a specialist (eg, general practitioner) could prescribe interferon-free HCV DAAs. Specialist only meant that the criteria required that the prescriber worked within a specialised field. Options included, but were not limited to, hepatologist, infectious disease specialist, internal medicine specialist, and gastroenterologist.

If a country or jurisdiction allowed a general practitioner to prescribe HCV DAAs but these therapies were not reimbursed, then this event was categorised as a restriction (ie, specialist only), because we were specifically interested in access to reimbursed therapies. Moreover, given that the study focus was specific to prescribing, whether a general practitioner or nurse practitioner could treat and monitor a patient who received interferon-free HCV DAAs was not recorded. HIV co-infection categories were: prioritised, eligible, none listed, and not available. Prioritised meant that people with HIV and HCV co-infection were given priority for treatment reimbursement (ie, had fewer reimbursement restrictions) over individuals with $\mathrm{HCV}$ alone. Eligible meant that people with HIV and HCV co-infection were subject to the same restriction criteria as individuals with HCV alone. Other was a possible category for any of the restriction criteria, when appropriate. Data were organised by use of descriptive statistics with Microsoft Excel (version 2010). Using separate Excel spreadsheets, two study authors (ADM and EBC) categorised the outcome criteria of about half of the European countries and jurisdictions each. Once completed, the same two study authors independently cross-checked each other's categorisation against the documentation. Relevant study authors were then contacted when further clarification was needed to resolve any inconsistencies. After this stage, information was updated as appropriate.

\section{Findings}

All European countries and jurisdictions $(100 \%, n=35)$ provided reimbursement for DAAs to treat HCV infection. As of Aug 1, 2017, the most commonly reimbursed therapy was ombitasvir, paritaprevir, and ritonavir, with dasabuvir, and with or without ribavirin (reimbursement available in 33 [94\%] countries). Sofosbuvir and daclatasvir with or without ribavirin was the least likely to be reimbursed (22 [63\%] countries). Most countries reimbursed sofosbuvir and ledipasvir with or without ribavirin (31 [89\%] countries), and elbasvir and grazoprevir with or without ribavirin (32 [91\%] countries), and 26 (74\%) countries reimbursed sofosbuvir and velpatasvir with or without ribavirin, while $29(83 \%)$ countries reimbursed sofosbuvir with ribavirin. Some countries, namely Estonia, Latvia, Lithuania, Malta, and Romania, had comparatively fewer therapeutic options than did other countries that reimbursed all HCV DAAs (figure 1). 16 (46\%) countries and jurisdictions required evidence of fibrosis of at least stage F2 (METAVIR or equivalent). Specifically, 10 $(29 \%)$ countries and jurisdictions required a minimum stage of F2; five (14\%) countries required a minimum fibrosis stage of $\mathrm{F} 3$; one (3\%) country (Malta) required a minimum 
fibrosis stage of F4; 13 (37\%) countries had no fibrosis stage restrictions; and six (17\%) countries had an additional requirement (eg, point system regardless of fibrosis stage; figure 2). In some countries, fibrosis stage was dependent on genotype. For example, Norway had no fibrosis stage restrictions for genotypes 1 and 4 (figure 1). The clinical recommendation in Norway was also age-dependent. People who were infected with genotype 2 or 3 , were younger than 40 years, and did not have cirrhosis, were offered peginterferon plus ribavirin for 12 weeks as the first line of therapy $(19,20)$. In Austria, Switzerland, and Liechtenstein, the HCV DAAs prescribed depended on the fibrosis stage. For example, sofosbuvir and ledipasvir with or without ribavirin, and sofosbuvir and velpatasvir with or without ribavirin had a minimum requirement of fibrosis stage F2; whereas elbasvir and grazoprevir with or without ribavirin had no restrictions based on fibrosis stage for individuals infected with genotypes 1 and 4 (21-24).

Although 29 (83\%) countries and jurisdictions had no listed restrictions for drug or alcohol use, six (17\%) countries required abstinence from drug and alcohol use before treatment ( $\geq 6$-month abstinence; figure 3 ). This restriction could include, but was not limited to, toxicological reports (eg, urine drug screening) every 3 months while taking DAAs to verify abstinence, as required in Croatia (appendix $\mathrm{p} 2$ ). To receive reimbursed therapy in Hungary, people actively using injection drugs or alcohol needed a psychiatrist consultation to support their capability and compliance for treatment and confirm no active injection drug use. In Romania, people with HIV and HCV co-infection had to have a negative drug test to receive reimbursed therapy; this restriction did not seem to apply to people with HCV alone. In Liechtenstein and Switzerland, people who inject drugs were prioritised for treatment with no fibrosis stage restriction (although fibrosis stage restrictions were in place in these countries for non-drug users).

Most countries and jurisdictions in Europe (33 [94\%] countries) required a specialist, most often a gastroenterologist, hepatologist, internal medicine specialist, or infectious disease specialist, to prescribe reimbursed DAAs for HCV (figure 4). In England, general practitioners could prescribe DAAs, although specialist input from a local multi-disciplinary committee was required. Operational Delivery Networks, established by the National Health Service in England, are committees that oversee patient care and HCV treatment, determine who can prescribe DAAs for HCV, and prioritises patients for therapy. In Germany, all general practitioners could prescribe reimbursed DAAs for HCV.

Certain countries, such as France, allowed general practitioners trained in HCV care to monitor patients once HCV therapy had started. However, France still required a specialist to prescribe DAAs. Some countries provided a list of specialist prescribers that patients needed to visit to receive a prescription for DAAs, whereas other countries-Austria, Czech Republic, Slovakia, and Slovenia-provided a list of specialist centres that dispense DAAs. Therefore, not all specialists were able to prescribe DAAs for HCV. Lastly, most European countries and jurisdictions (34 [97\%] countries) had no additional restrictions for people coinfected with HIV and HCV. Among the 22 countries that had minimum fibrosis stage restrictions (including those in the category Other) for individuals infected with HCV alone, nine $(41 \%)$ of these countries (Belgium, Croatia, Czech Republic, Greece, Liechtenstein, Malta, Slovakia, Slovenia, and Switzerland) had no fibrosis stage restrictions for people coinfected with HIV and HCV; hence, these patients were prioritised for treatment (figure 5). In Romania, these patients needed to provide evidence of a negative drug test.

\section{Discussion}

This study demonstrated several similarities concerning access and reimbursement restrictions for DAAs in Europe. Restrictions based on specialist prescription were almost universal, with $94 \%(n=33)$ of countries requiring a specialist to prescribe DAAs. Disease- 
based restrictions were common, with nearly half of countries and jurisdictions restricting DAAs to people with substantial liver disease $(\geq F 2)$. Furthermore, six $(17 \%)$ countries required patient abstinence from drug or alcohol use to qualify for reimbursed therapies. These restrictions are not in agreement with the 2016 European Association for the Study of Liver (EASL) recommendations on the treatment of hepatitis $C$, which state that all patients without contraindications to therapy should be offered treatment.12 Additionally, these restrictions will need to be minimised to meet the $\mathrm{WHO}$ target of eliminating viral hepatitis as a major public health threat by 2030 (18). To our knowledge, this is the first study to review HCV DAA reimbursement restrictions in Europe, and its primary findings have the potential to influence clinical practice and policy. Similar studies on DAA restrictions have been used in legal and advocacy efforts to remove (or reduce) DAA reimbursement restrictions in Canada and the USA.8-10 A follow-up study of reimbursement in the USA showed that states decreased reimbursement restrictions over a 2-year period.8,10 This finding highlights the importance of collecting data for Europe, to provide a baseline from which to compare DAA access in the coming years. A follow-up study on DAA access and restrictions in Europe would be beneficial.

There were some limitations in the present study. Given that there was no systematic repository or standardised system for the collation of reimbursement restriction information, we relied on an extensive selection of documents and ongoing consultation with study authors to verify the accuracy of data. This study only evaluated written restrictions, and the prescribing practices of clinicians might differ from reimbursement criteria. For example, among countries that have no listed drug use restriction, people who inject drugs could be much less likely to be offered DAAs. Further, if additional restrictions were reviewed, even greater reimbursement discrepancies across countries and jurisdictions might have been revealed. For example, in Belgium, both an elastography test and biomarker score (or alternatively, a liver biopsy) were required to assess fibrosis stage (25). Countries might also differ on policies for re-treatment.

Moreover, the present study did not review variability within countries. People who reside in rural areas or do not have private health insurance plans might find it more difficult to access reimbursed therapies. This topic warrants further study. Research on heterogeneity in health-care systems in Europe, specifically how medication coverage (with varying deductible or co-pay arrangements) affects treatment access at the patient level, is also needed. With respect to reimbursement restrictions, we did not specifically investigate the distinction between access and choice. In some countries, the available regimens might have been limited by conditions put in place by the reimbursement agency, which might have restricted the selection of DAAs that physicians could choose to prescribe. Lastly, timeliness of data was a limitation in this study.

Although efforts were made to include the most current information, online information and documentation concerning DAA availability and reimbursement restrictions frequently changed as therapies became approved and governments negotiated new agreements with pharmaceutical companies. We did not contact government ministries to verify information, which is a notable limitation of this study. Nevertheless, this study provides an accurate assessment of reimbursement restrictions in Europe as of Aug 1, 2017. The considerable heterogeneity in DAA availability and reimbursement restrictions observed in Europe is consistent with previous studies that have evaluated regional differences in reimbursement in Canada (9) and the USA $(8,10)$.

Notably, 33 (94\%) countries and jurisdictions in Europe required a specialist to prescribe DAAs compared with up to $42 \%$ of provinces and territories in Canada (9) and $67 \%$ of states in the USA (10). Even in European countries and jurisdictions where primary care providers can prescribe DAAs, restrictions are in place through managed care networks (eg, in England) or physicians are concerned with medical liability claims (eg, in Germany). In 
Australia, all medical providers (including primary care clincians and drug or alcohol clinicians) can prescribe DAAs. Less experienced prescribers are required to consult a gastroenterologist, hepatologist, or infectious disease specialist to confirm the appropriateness of DAA treatment. Under this system, an increasing proportion of DAA prescriptions are completed by primary care and non-specialist providers (26). Several factors will probably affect current and future prescriber patterns, including involvement of nonspecialists. Countries with more concentrated geography (less rural or remote regions), well developed specialist treatment centres with extensive referral pathways, and fewer highly marginalised patients, might not require substantial involvement from non-specialists. Countries that expand prescriber protocols to include non-specialists can be encouraged by evidence that HCV treatment outcomes are similar between primary care providers and specialists $(27,28)$.

The WHO viral hepatitis strategy states that everyone living with viral hepatitis should have access to safe, affordable, and effective care (18). However, nearly half of European countries have restricted DAA reimbursement to people with, at minimum, moderate fibrosis $(\geq F 2)$, which is also inconsistent with the 2016 EASL recommendations on the treatment of hepatitis $C$ (12). The restriction of DAA treatment to patients with more advanced liver disease (and other criteria such as genotype and age, as seen in Norway) is a form of prioritisation in the context of high DAA pricing related to potential health budget concerns.

These constraints are, presumably, an interim strategy while countries await the development of further treatment infrastructure and declines in DAA pricing. Restrictions regarding stage of liver disease will probably be removed in many countries in the near future, as happened in Spain in June, 2017. Successful treatment of HCV infection reduces progression of liver disease (29) and decreases all-cause mortality in people with advanced liver disease (30). Treatment of those with the greatest risk of transmission (eg, people who inject drugs) helps to prevent onward HCV transmission (31). As such, increasing access to DAA therapy will yield both individual and public health benefits. $17 \%$ of European countries restricted access to DAAs among people with recent drug or alcohol use.

Perceptions about poor adherence resulting from ongoing substance use and risk of reinfection are often put forward as reasons to withhold HCV therapy from people who inject drugs $(32,33)$. A study $(32)$ of HCV practitioners $(72 \%$ were gastroenterology and hepatology specialists) in the DAA era found that only $15 \%$ were willing to treat people who were actively injecting drugs. Data have demonstrated excellent adherence and response to DAAs for HCV among people who recently used drugs (34-39), people receiving opioid substitution therapy (40-48), and people who recently injected drugs (49-51). Rates of reinfection among people who inject drugs are also relatively low $(52,53)$. In light of this evidence, there has been some debate as to the ethical justification for withholding therapy from people with ongoing drug or alcohol use (54).

This study has several key implications for clinicians and policy makers. European countries should focus on removing restrictions that prevent primary care, and drug and alcohol care providers from prescribing DAAs. The 2016 EASL recommendations on treatment of hepatitis $\mathrm{C}$ provide guidance to ensure $\mathrm{HCV}$ is appropriately managed by health-care providers (12).

Mobilisation of specialists to mentor and train primary care and drug and alcohol care providers, simplification of pathways for the referral of people with advanced liver disease (aspartate aminotransferase-to-platelet ratio index [APRI] $>1$ ) to specialists, and provision of HCV education and training for nurses, primary care providers, and drug and alcohol care providers would all help to increase access to reimbursed DAAs. 
The upcoming availability of pangenotypic DAAs will also make it easier for primary care and drug and alcohol care providers to prescribe DAAs. Although there is no one size fits all strategy for the widespread implementation of DAAs for HCV, a substantial increase in testing, linkage to care, and treatment-particularly among high-risk groups-will be required to reduce HCV incidence, HCV prevalence, and HCV-related morbidity and mortality $(5,17$, $55,56)$.

Efforts are needed to ensure appropriate monitoring and evaluation of country-level responses to HCV infection (which could then be added to national strategies and action plans) and the effect of DAA treatment uptake on HCV-related morbidity and mortality (18, 57-59). Updated epidemiological data for the morbidity and mortality of HCV-related burden $(14,60)$ would probably further strengthen national level policy support for increased access to DAAs for HCV. Restrictions on DAA reimbursement throughout Europe are undoubtedly linked to the high list price of DAA regimens. As a result, current reimbursement restrictions in most European countries are related to prioritisation. The details of DAA prices (or discounts to list prices) are often not readily available, but there are considerable betweencountry differences in the discounts to list prices across Europe. Broad access to DAAs requires negotiations to decrease DAA prices (or discounts to list prices) to facilitate removal of restrictions.

Greater transparency regarding these negotiations and outcomes is important for the broader strategic development towards healthcare access for all. WHO mortality and incidence elimination targets are achievable and cost-effective (61) in many countries but will require the collective efforts of researchers, health-care providers, policy makers, the affected community, and the pharmaceutical industry, to succeed.

\section{Contributors}

JG, ADM, JVL, EBC, and SNi were responsible for study conception and design. A study concept sheet was circulated to all authors to comment on the study design. All authors contributed to data acquisition. ADM, EBC, and SNi facilitated document access. Document searches were also conducted independently by ADM, EBC, and SNi to further corroborate search findings. ADM and EBC categorised the outcome criteria. ADM, JG, GJD, EBC, and JVL contributed to the drafting of the report.

\section{Declaration of interests}

AA has received a research grant from Gilead Sciences, is on the advisory board for Janssen, Merck Sharp \& Dohme, Bristol-Myers Squibb, Gilead Sciences, and AbbVie, and has received personal fees from Janssen, Merck Sharp \& Dohme, Bristol-Myers Squibb, Gilead Sciences, and AbbVie, outside the submitted work. PB has received grants and personal fees from AbbVie, Merck Sharp \& Dohme, Gilead Sciences, and Bristol-Myers Squibb, outside the submitted work. OD has received grants from Gilead Sciences, and grants and personal fees from AbbVie and Merck Sharp \& Dohme, outside the submitted work. CS-D has received grants from Gilead Sciences, outside the submitted work. GJD has received grants from AbbVie, Merck Sharp \& Dohme, Bristol-Myers Squibb, Janssen, and Roche, personal fees from Gilead Sciences, AbbVie, Merck Sharp \& Dohme, Bristol-Myers Squibb, Janssen, Roche, GlaxoSmithKline, and Abbott Diagnostics, and non-financial support from Gilead Sciences, AbbVie, Merck Sharp \& Dohme, Bristol-Myers Squibb, and Roche, outside the submitted work. RF has received grants and personal fees from AbbVie, Gilead Sciences, Merck Sharp \& Dohme, and Roche, and personal fees from Janssen, outside the submitted work. GRF has received grants and personal fees from Merck Sharp \& Dohme, Gilead Sciences, and AbbVie during the conduct of the study, outside the submitted 
work, and is the National Clinical Lead for Hepatitis C in England. JG has received grants from AbbVie, Bristol-Myers Squibb, and Cepheid, and grants and personal fees from Gilead Sciences and Merck Sharp \& Dohme, outside the submitted work. LG has received personal fees from AbbVie, Bristol-Myers Squibb, Gilead Sciences, and Merck Sharp \& Dohme, and is part of the consulting and advisory board for Merck Sharp \& Dohme, AbbVie, and Gilead Sciences. DG has received personal fees (honoraria) from Gilead Sciences, AbbVie, and Merck for lectures not related to products, outside the submitted work. MH has received personal fees from Merck Sharp \& Dohme, AbbVie, and Gilead Sciences, outside the submitted work. LJ has received personal fees and non-financial support from Merck Sharp \& Dohme and AbbVie, outside the submitted work. PJ has received personal fees and nonfinancial support from AbbVie and Gilead Sciences, and personal fees from Merck Sharp \& Dohme, outside the submitted work. MK has received grants and personal fees from Gilead Sciences and personal fees from AbbVie and Merck Sharp \& Dohme, outside the submitted work. JVL has received research grants and personal fees from AbbVie, Gilead Sciences, and Merck Sharp \& Dohme, outside the submitted work. MMak has been an investigator in clinical trials for Novartis, Bristol-Myers Squibb, Janssen-Cilag, AbbVie, Roche, BoehringerIngelheim, Merck Sharp \& Dohme, and Regulus, and has received personal fees from Janssen-Cilag, AbbVie, Roche, Boehringer-Ingelheim, Merck Sharp \& Dohme, and Gilead Sciences, outside the submitted work. RTM has received personal fees, advisory board fees, and speaker fees from AbbVie, Merck Sharp \& Dohme, and Gilead Sciences. SO has received personal fees from Merck Sharp \& Dohme, outside the submitted work. CR has received speaker fees from Janssen-Cilag, Ferrer-Brainfarma, Pfizer, ReckittBenckiser/Indivior, Lundbeck, Otsuka, Servier, Lilly, GlaxoSmithKline, Astra, Sanofi, and Excelsis, received financial compensation for participation as a member of Janseen-Cilag, Indivior, Gilead Sciences, Merck Sharp \& Dohme, and Munidipharma advisory boards, and received grants funded by Reckitt-Benckisert/Indivior and Gilead Sciences, outside the submitted work. AO has received personal, travel, speaker, and consultancy fees from AbbVie, grants, personal fees, travel fees, and consultancy fees from Gilead Sciences, personal fees from Bristol-Myers Squibb, and travel fees from Merck Sharp \& Dohme, outside the submitted work. J-MP has received grants and personal fees from Abbvie, grants and personal fees from Gilead Sciences, and personal fees from Merck, outside the submitted work. JP has received non-financial support from Gilead Sciences and AbbVie, outside the submitted work. MS has received speaker fees from AbbVie, Gilead Sciences, and Merck, and has been an advisor for AbbVie, Gilead Sciences, and Merck, outside the submitted work. JS has received grants and personal fees from AbbVie, and personal fees from Merck, Gilead Sciences, Bristol-Myers Squibb, and Herbacos Recordati, outside the submitted work. GR has received research grants from Merck Sharp \& Dohme, AbbVie, Janssen Pharmaceuticals, and has acted as a consultant and advisor for Gilead Sciences, AbbVie, Merck Sharp \& Dohme, and Bristol-Myers Squibb. IT has received honoraria for lectures from Merck Sharp \& Dohme and AbbVie. MvdV has received personal fees from AbbVie, Bristol-Myers Squibb, Johnson \& Johnson, and ViiV Healthcare, grants and personal fees from Gilead Sciences, and grants, personal fees, and non-financial support from Merck Sharp \& Dohme, outside the submitted work. AV has received personal fees and non-financial support from Gilead Sciences, and personal fees from Merck Sharp \& Dohme and AbbVie during the conduct of this study.

SNi declares non-financial support from INHSU.

ADM, EBC, HA, MB, MMai, MMat, IC, LGK, SNo, and ST declare no competing interests. 
We thank the following people for their assistance with retrieval and interpretation of documentation: Havard Midgard (Department of Infectious Diseases, Akershus University Hospital, Norway; Institute for Clinical Medicine, University of Oslo, Norway; Department of Gastroenterology, Oslo University Hospital, Norway), Ecaterina Filep, Gerard Estivill Mercade, Marcel Schulz, Rainer Puhr (The Kirby Institute, UNSW, Sydney, NSW, Australia), Petros Katsioloudes (Ministry of Health, Cyprus), and loannis Demetriades (Grigorios Clinic, Larnaca General Hospital, Cyprus). We also thank The All Wales Therapeutics and Toxicology Centre (Penarth, UK), and the National Institute for Health Research Health Protection Research Unit in Evaluation of Interventions (University of Bristol, UK). ADM holds a University International Postgraduate Award from UNSW (Sydney, Australia). ADM and EBC are supported by the CanHepC Trainee Program (Canada). JG and GJD are supported by a National Health and Medical Research Council Career Development Fellowship. The Kirby Institute is funded by the Australian Government Department of Health. The views expressed in this publication do not necessarily represent the position of the Australian Government.

\section{References}

1 Polaris Observatory HCV Collaborators. Global prevalence and genotype distribution of hepatitis C virus infection in 2015: a modelling study. Lancet Gastroenterol Hepatol 2017; 2: $161-76$.

2 WHO. Global hepatitis report, 2017. April, 2017. http://apps.who.int/iris/bitstream/10665/255016/1/9789241565455-eng.pdf?ua=1 (accessed June 23, 2017).

3 GBD 2013 Mortality and Causes of Death Collaborators. Global, regional, and national age-sex specific all-cause and cause-specific mortality for 240 causes of death, 1990-2013: a systematic analysis for the Global Burden of Disease Study 2013. Lancet 2015; 385: 11771.

4 Dore GJ, Feld JJ. Hepatitis C virus therapeutic development: in pursuit of "perfectovir". Clin Infect Dis 2015; 60: 1829-36.

5 Wedemeyer H, Dore GJ, Ward JW. Estimates on HCV disease burden worldwide-filling the gaps. J Viral Hepat 2015; 22 (suppl 1): 1-5.

6 Gane E, Kershenobich D, Seguin-Devaux C, et al. Strategies to manage hepatitis C virus (HCV) infection disease burden-volume 2. J Viral Hepat 2015; 22 (suppl 1): 46-73.

7 Nahon P, Bourcier V, Layese R, et al. Eradication of hepatitis C virus infection in patients with cirrhosis reduces risk of liver and non-liver complications. Gastroenterology 2017; 152: 142-56.

8 Barua S, Greenwald R, Grebely J, Dore GJ, Swan T, Taylor LE. Restrictions for Medicaid reimbursement of sofosbuvir for the treatment of hepatitis $C$ virus infection in the United States. Ann Intern Med 2015; 163: 215-23.

9 Marshall AD, Saeed S, Barrett L, et al. Restrictions for reimbursement of direct-acting antiviral treatment for hepatitis $C$ virus infection in Canada: a descriptive study. CMAJ Open 2016; 4: E605-14.

10 Ooka K, Connolly JJ, Lim JK. Medicaid reimbursement for oral direct antiviral agents for the treatment of chronic hepatitis C. Am J Gastroenterol 2017; 112: 828-32. 
11 AASLD/IDSA HCV Guidance Panel. Hepatitis C guidance: AASLD-IDSA

recommendations for testing, managing, and treating adults infected with hepatitis $C$ virus.

Hepatology 2015; 62: 932-54.

12 European Association for the study of the Liver. EASL recommendations on treatment of hepatitis C 2016. J Hepatol 2017; 66: 153-94.

13 WHO. Guidelines for the screening, care and treatment of persons with chronic hepatitis C infection. 2016. http://www.who.int/hepatitis/publications/hepatitis-c-guidelines-2016/en/ (accessed Jan 12, 2017).

14 Razavi H, Robbins S, Zeuzem S, et al. Hepatitis C virus prevalence and level of intervention required to achieve the WHO targets for elimination in the European Union by 2030: a modelling study. Lancet Gastroenterol Hepatol 2017; 2: 325-36.

15 Hajarizadeh B, Grebely J, Dore GJ. Epidemiology and natural history of HCV infection. Nat Rev Gastroenterol Hepatol 2013; 10: 553-62.

16 Hatzakis A, Chulanov V, Gadano AC, et al. The present and future disease burden of hepatitis $\mathrm{C}$ virus $(\mathrm{HCV})$ infections with today's treatment paradigm-volume 2. J Viral Hepat 2015; 22 (suppl 1): 26-45.

17 Saraswat V, Norris S, de Knegt RJ, et al. Historical epidemiology of hepatitis $\mathrm{C}$ virus (HCV) in select countries—volume 2. J Viral Hepat 2015; 22 (suppl 1): 6-25.

18 WHO. Global health sector strategy on viral hepatitis 2016-2021. Towards ending viral hepatitis. June, 2016. http://www.who.int/hepatitis/strategy2016-2021/ghss-hep/en/ (accessed May 21, 2017).

19 Sykehusinnkjop HF. HCV guidelines for the Norwegian Health Authorities. Feb 8, 2017. http://sykehusinnkjop.no/wp-content/uploads/2017/02/LIS-HCV-anbefalinger-2017leverand\%C3\%B8rer.pdf (accessed May 10, 2017).

20 Norwegian Medical Association. Clinical recommendations for hepatitis $C$ treatment in Norway. March, 2017. http://www.hepatittfag.no/om\#bakgrunn (accessed May 5, 2017; in Norwegian).

21 Schweizerische Eidgenossenschaft. Index of the specialty list directories. 2017. Online Drug Formulary. http://www.spezialitaetenliste.ch/ (accessed Feb 23, 2017).

22 Chandrasekhar A. Swiss hepatitis $C$ sufferers to get full access to expensive drug. June 26, 2017. https://www.swissinfo.ch/eng/zepatier- swiss-hepatitis-c-sufferers-to-get-fullaccess-to-expensivedrug/43288924 (accessed June 27, 2017).

23 Erstattungskodex (EKO). In focus tips. New in EKO. May, June, and July 2017. 2017. http://www.bgkk.at/cdscontent/load?contentid=10008.642874\&version=1499412330 (accessed Aug 1, 2017).

24 Swiss Confederation. Drugs against hepatitis C: strong price reduction and extended remuneration. 2017. www.bag.admin.ch/bag/de/home/aktuell/news/news-26-06-2017.html (accessed June 27, 2017).

25 Belgian Association for the Study of the Liver. Belgian HCV therapy guidance update January 2017. 
http://www.basl.be/sites/default/files/Belgian\%20HCV\%20therapy\%20guidance\%20update\% 20january\%202017 final 25012017.pdf (accessed May 19, 2017).

26 The Kirby Institute. Monitoring hepatitis C treatment uptake in Australia. Issue 6.

February, 2017. https://kirby.unsw.edu.au/sites/default/files/kirby/report/Monitoring-hep-Ctreatment-uptake-in-Australia Iss6-FEB17.pdf (accessed March 17, 2017).

27 Arora S, Thornton K, Murata G, et al. Outcomes of treatment for hepatitis C virus infection by primary care providers. N Engl J Med 2011; 364: 2199-207.

28 Kattakuzhy SM, Gross C, Teferi G, et al. High efficacy of HCV treatment by primary care providers: the ASCEND study. Conference on retroviruses and opportunistic infections. Boston, MA, USA; Feb 22-25, 2016. http://hepcasia.com/wpcontent/uploads/2015/03/HCVtreatment-via-primary-careproviders.pdf (accessed July 5, 2017).

29 Grebely J, Dore GJ. What is killing people with hepatitis C virus infection? Semin Liver Dis 2011; 31: 331-39.

30 van der Meer AJ, Wedemeyer $\mathrm{H}$, Feld JJ, et al. Life expectancy in patients with chronic HCV infection and cirrhosis compared with a general population. JAMA 2014; 312: 1927-28.

31 Martin NK, Vickerman P, Grebely J, et al. Hepatitis C virus treatment for prevention among people who inject drugs: Modeling treatment scale-up in the age of direct-acting antivirals. Hepatology 2013; 58: 1598-609.

32 Asher AK, Portillo CJ, Cooper BA, Dawson-Rose C, Vlahov D, Page KA. Clinicians' views of hepatitis $C$ virus treatment candidacy with direct-acting antiviral regimens for people who inject drugs. Subst Use Misuse 2016; 51: 1218-23.

33 Grebely J, Oser M, Taylor LE, Dore GJ. Breaking down the barriers to hepatitis C virus (HCV) treatment among individuals with HCV/HIV coinfection: action required at the system, provider, and patient levels. J Infect Dis 2013; 207 (suppl 1): S19-25.

34 Norton BL, Fleming J, Steinman M, et al. High HCV cure rates for drug users treated with direct acting antiviral theray at an urban primary care clinic. Int J Drug Policy 2017; 47: 196201.

35 Conway B, Raycraft T, Bhutani Y, et al. Efficacy of all-oral HCV therapy in people who inject drugs. Hepatology 2016; 64: 990A (abstr).

36 Sulkowski M, Ward K, Falade-Nwulia O, et al. Randomized controlled trial of cash incentives or peer mentors to improve HCV linkage and treatment among HIV/HCV coinfected persons who inject drugs: the CHAMPS Study. J Hepatol 2017; 66: S719.

37 Mason K, Dodd Z, Guyton M, et al. Understanding real-world adherence in the directly acting antiviral era: a prospective evaluation of adherence amongst people with a history of drug use at a community-based program in Toronto, Canada. Int J Drug Policy 2017; 47: 202-08.

38 Morris L, Smirnov A, Kvassay A, et al. Initial outcomes of integrated community-based hepatitis C treatment for people who inject drugs: findings from the Queensland Injectors' Health Network. Int J Drug Policy 2017; published online June 27.

DOI:10.1016/j.drugpo.2017.05.056. 
39 Read P, Lothian R, Chronister K, et al. Delivering direct acting antiviral therapy for hepatitis $\mathrm{C}$ to highly marginalised and current drug injecting populations in a targeted primary health care setting. Int J Drug Policy 2017; published online June 4. DOI:10.1016/j. drugpo.2017.05.032.

40 Puoti M, Cooper C, Sulkowski MS, et al. ABT-450/r/Ombitasvir plus dasabuvir with or without ribavirin in HCV genotype 1-infected patients receiving stable opioid substitution treatment: pooled analysis of efficacy and safety in phase 2 and phase 3 trials.

Hepatology 2014; 60: 1135a-6a.

41 Feld JJ, Kowdley KV, Coakley E, et al. Treatment of HCV with ABT-450/r-ombitasvir and dasabuvir with ribavirin. N Engl J Med 2014; 370: 1594-603.

42 Zeuzem S, Ghalib R, Reddy KR, et al. Grazoprevir-elbasvir combination therapy for treatment-naive cirrhotic and noncirrhotic patients with chronic hepatitis $\mathrm{C}$ virus genotype 1 , 4, or 6 infection: a randomized trial. Ann Intern Med 2015; 163: 1-13.

43 Grebely J, Dore GJ, Zeuzem S, et al. Efficacy and safety of sofosbuvir/velpatasvir in patients with chronic hepatitis $C$ virus infection receiving opioid substitution therapy: analysis of phase 3 ASTRAL trials. Clin Infect Dis 2016; 63: 1479-81.

44 Grebely J, Mauss S, Brown A, et al. Efficacy and safety of ledipasvir/sofosbuvir with and without ribavirin in patients with chronic HCV genotype 1 infection receiving opioid substitution therapy: analysis of phase 3 ION trials. Clin Infect Dis 2016; 63: 1405-11.

45 Grebely J, Puoti M, Wedemeyer H, et al. Safety and efficacy of ombitasvir, paritaprevir/ritonavir and dasabuvir with or without ribavirin in chronic hepatitis $\mathrm{C}$ patients receiving opioid substitution therapy: a pooled analysis across 12 clinical trials. $J$ Hepatol 2017; 66: S514.

46 Grebely J, Jacobson IM, Kayali Z, et al. Sof/vel/vox for 8 or 12 weeks is well tolerated and results in high SVR12 rates in patients receiving opioid substitution therapy. $J$ Hepatol 2017; 66: S513.

47 Lalezari J, Sullivan JG, Varunok P, et al. Ombitasvir/paritaprevir/r and dasabuvir plus ribavirin in HCV genotype 1-infected patients on methadone or buprenorphine. $J$ Hepatol 2015; 63: 364-69.

48 Dore GJ, Altice F, Litwin AH, et al. Elbasvir-grazoprevir to treat hepatitis $\mathrm{C}$ virus infection in persons receiving opioid agonist therapy: a randomized trial. Ann Intern Med 2016; 165: 625-34.

49 Bouscaillou J, Kikvidze T, Butsashvili M, et al. Effectiveness of DAA-based treatment of $\mathrm{HCV}$ in active people who inject drugs living in middle income countries (MIC): the results of a prospective cohort study in Tbilisi, Georgia. J Hepatol 2017; 66: S409.

50 Boglione L, Mornese Pinna S, De Nicolo A, et al. Treatment with direct-acting antiviral agents of hepatitis $C$ virus infection in injecting drug users: a prospective study. J Viral Hepat 2017; published online March 26. DOI:10.1111/jvh.12711.

51 Grebely J, Dalgard O, Conway B, et al. Efficacy and safety of sofosbuvir/velpatasvir in people with chronic hepatitis $C$ virus infection and recent injecting drug use: the SIMPLIFY study. J Hepatol 2017; 66: S513. 
52 Dore GJ, Altice F, Litwin AH, et al. Elbasvir/grazoprevir to treat HCV infection in persons receiving opioid agonist therapy: a randomized controlled trial (C-EDGE CO-STAR). Ann Intern Med 2016; 165: 625-34.

53 Aspinall EJ, Corson S, Doyle JS, et al. Treatment of hepatitis C virus infection among people who are actively injecting drugs: a systematic review and meta-analysis. Clin Infect Dis 2013; 57 (suppl 2): S80-89.

54 Grebely J, Haire B, Taylor LE, et al. Excluding people who use drugs or alcohol from access to hepatitis $C$ treatments-Is this fair, given the available data? J Hepatol 2015; 63: 779-82.

55 Liakina V, Hamid S, Tanaka J, et al. Historical epidemiology of hepatitis C virus (HCV) in select countries-volume 3. J Viral Hepat 2015; 22 (suppl 4): 4-20.

56 Bruggmann $\mathrm{P}$, Berg $\mathrm{T}$, Ovrehus AL, et al. Historical epidemiology of hepatitis $\mathrm{C}$ virus (HCV) in selected countries. J Viral Hepat 2014; 21 (suppl 1): 5-33.

57 WHO. Manual for the development and assessment of national viral hepatitis plans. September, 2015. www.who.int/hepatitis/publications/manual-hep-plan/en/ (accessed May 19, 2017).

58 European Liver Patients Association. The 2016 Hep-Core report. Monitoring the implementation of hepatitis B and C policy recommendations in Europe. March, 2017. http://www.elpa.eu/sites/default/files/project-documents/HepCORE full report 21Mar2017 errata Final.pdf (accessed May 30, 2017).

59 WHO. Regional committee for Europe 66th session. Action plan for the health sector response to viral hepatitis in the WHO European Region. September, 2016.

http://www.euro.who.int/en/about-us/governance/regional-committee-for-europe/66thsession/documentation/working-documents/eurrc6610-action-plan-for-thehealth-sectorresponse-to-viral-hepatitis-in-the-who-european-region (accessed June 23, 2017).

60 Muhlberger N, Schwarzer R, Lettmeier B, Sroczynski G, Zeuzem S, Siebert U. HCVrelated burden of disease in Europe: a systematic assessment of incidence, prevalence, morbidity, and mortality. BMC Public Health 2009; 9: 34.

61 Scott N, McBryde ES, Thompson A, Doyle JS, Hellard ME. Treatment scale-up to achieve global HCV incidence and mortality elimination targets: a cost-effectiveness model. Gut 2016; 66: 1507-15. 